Robin Lane Fox

\section{Der Englische Gärtner}

Klett-Cotta, Stuttgart 2018, 457 Seiten

zahlreiche farbige Abbildungen und Fotos

$15,5 \times 22,5 \mathrm{~cm}$

aus dem Englischen übersetzt von Susanne Held

ISBN 978-3-608-96220-8; 32 Euro

Der Klett-Cotta-Verlag legt hier die deutsche Übersetzung des 2010 erstmals in New York erschienenen Buches „Thoughtful Gardening“ von R. L. Fox vor. Nach dem Studium der Altertumswissenschaften an der Universität Oxford begann Fox (Jahrgang 1946) seine Karriere als Gärtner im Botanischen Garten in München, bevor er ab 1979 bis zu seiner Pensionierung als „Garden Master" seines Oxforder Colleges tätig war.

In 82 Geschichten berichtet Fox über seine Erfahrungen und Gedanken zu einzelnen Blütenpflanzen. In den vier Kapiteln Winter, Frühling, Sommer und Herbst schreibt er in gut lesbarer Weise über eine Vielzahl von blühenden Pflanzengattungen. Für den Autor sind Gärten menschliche Schöpfungen, die vom persönlichen Charakter der Gärtner ebenso geprägt sind wie von Kunst, Geschichte, Politik und Wissenschaft. Durch seine Texte tauchen wir ein in britische Gartentradition, vergessenes Wissen über Pflanzen und geniale Gärtner.

Neugierig macht er den Leser mit geheimnisvollen Überschriften wie: Lady-Killing, Schätze aus China, Wiedersehen mit Rosemary oder der Hort des Friedens alter Zeiten. Andere Kapitel wie Jardin Majorelle, Frühe Kirschblüten, Vom Kasten ins Beet, Tierische Tunichtgute, Kränkelnde Kastanienbäume, Hortensien unter Bäumen, Begehrenswerte Dahlien oder Das botanische Palermo verraten direkt die diskutierten Themen. An seinen profunden Kenntnissen von Sorten der
Magnolien, Hortensien oder Rhododendren lässt er Leserinnen und Leser teilhaben. Mit manchen Vorurteilen über die Winterhärte einzelner Sorten kann er aufräumen, weil die Pflanzen sich in seinen Gärten in Bezug auf die Winterhärte besser als vermutet gehalten haben. Gute Ratschläge erhält man nicht zuletzt darüber, welche Pflanzen auf basischen oder sauren Böden gedeihen. Auch Hinweise auf Pflanzenschutzmittel sind zu finden. Erquickend ist seine ironische Darstellung eigener nicht immer ganz geglückter Pflanzungen.

Mit charmanten Zitaten von ihm bekannten Gartenliebhaberinnen und -liebhabern führt er durch die Gartengestaltung beispielsweise in China, Italien und der Normandie. Er lässt auch nicht die Ukraine und vor allem nicht England aus.

Man muss das Buch nicht in einem Stück durchlesen. Jede wenige Seiten lange Abhandlung ist für sich selbst ein Gewinn, ein Nachdenken über eigene Erfahrungen und Beobachtungen wird immer wieder unterbewusst herausgefordert. Es ist auch erlaubt, in Gedanken die Reisen des Autors unter die japanischen oder koreanischen Kirschblütenalleen mitzuerleben. Genauere Angaben, in welchen Gärten die Fotografien des Buches entstanden sind, werden in der Danksagung aufgelistet. Dadurch werden dem Leser Anregungen für verschiedene Gartenbesuche geliefert. Ein Register mit den wissenschaftlichen Namen der besprochenen Pflanzen würde dem Buch guttun und die Arbeit mit den darin enthaltenen Hinweisen erleichtern.

Zusammengefasst ist dies ein Buch, das jeder Anfänger als Quelle von Wissen nutzen kann und Interessierte einem Gartenliebhaber schenken sollten, dem sie Freund oder Freundin bleiben oder werden wollen.

Michael Paulitsch 